\title{
Cerebrovascular Permeability in Mechanically Induced Hypertension
}

\author{
SUKRITI NAG, DAVID M. ROBERTSON, HENRY B. DINSDALE
}

SUMMARY: Our previous studies of cerebrovascular permeability in angiotensin-induced acute hypertension demonstrated that the principal mechanism resulting in increased permeability is enhanced pinocytosis. In order to exclude the possibility that the enhanced pinocytosis was a direct effect of exogenous angiotensin, cerebrovascular permeability alterations were sludied in nonpharmacologically induced acute hypertension.

Rats receiving horseradish peroxidase (HRP) intravenously, were sacrificed $21 / 2$ minutes after the onset of hypertension induced by placing a clip on the abdominal aorta. These animals showed the same pattern of permeability alterations as had

RESUMÉ: Nos études préalables de la perméabilité cérébrovasculaire dans l'hypertension aigüee induite par l'angiotensine avaient démontré que le méchanisme principal de perméabilité augmentée était la pinositose accéléreé afin d'exclure la possibilité que cette pinositose accélérée soit un effet direct de l'angiotensine exogène, nous avons étudié les modifications de la perméabilité cérébrovasculaire dans l'hypertension induite non pharmacologiquement.

Des rats rendus hypertensifs par compression de l'aorte abdominale furent sacrifiés deux minutes et demie après le début de l'hypertension et après avoir reçu le HRP de façon intraveineuse. Nous avons observé le même patron de modifications been observed previously in animals with angiotensin-induced acute hypertension. Focal segments of penetrating arterioles in the temporal and parietal cortex showed increased permeability to HRP. Permeable vessels showed increased numbers of pinocytotic vesicles and the interendothelial junctions revealed no alterations. Enhanced pinocytosis appears to be the principal mechanism resulting in increased cerebrovascular permeability in this model as well suggesting that the alterations of cerebrovascular permeability observed previously in angio-tensin-induced acute hypertension occur due to the hypertensive state and are not a direct drug effect of exogenous angiotensin.

dans la perméabilité que lors des études avec l'angiotensine. Quatre segments d'artérioles pénétrant dans le cortex temporal ou pariétal montraient une perméabilité augmentée au $H R P$.

Les vaisseaux perméables indiquaient un nombre augmenté de vésicules pinositaires alors que les fonctions interendotéliales ne présentaient aucune altération.

Une pinositose augmentée semble donc être le méchanisme principal résultant en une perméabilité augmentée dans le modèle choisi, et suggère que les anomalies observées préalablement à la suite d'une hypertension induite sont dûes à l'état d'hypertension plutôt qu'à l'effet pharmacologique direct de l'angiotensine exogène.
From the Departments of Pathology and Medicine, Queen's University and Kingston General Hospital, Kingston, Ontario, Canada.

Supported by Medical Research Council of Canada, Grant No. MA-7191 and Ontario Heart Foundation.

Request for reprints to: Dr. S. Nag, Department of Pathology, Queen's University, Kingston, Ontario, Canada K7L 3N6.

\section{INTRODUCTION}

Alteration of blood-brain barrier (BBB) permeability leading to cerebral edema is a feature of human hypertensive encephalopathy. Interest in the mechanisms resulting in enhanced cerebrovascular permeability in this condition has led to several studies (Hansson et al, 1975; Nag et al, 1977, 1979; Nagy et al, 1979; Westergaard et al, 1977), utilizing the acute hypertension model in which hypertension was induced by pressor agents and horseradish peroxidase (HRP) was used as a marker of $B B B$ permeability alterations.

Our previous studies of cerebrovascular permeability in angiotensininduced acute hypertension (Nag et al, 1977, 1979), demonstrated that the principal mechanism resulting in early permeability alterations in focal segments of penetrating arterioles, particularly those in the second and third cortical layers is enhanced pinocytosis. A question arising from this work was whether the observed enhanced pinocytosis was associated with the presence of exogenous angiotensin and not a direct result of the induced hypertension.

This study describes the cerebrovascular permeability alterations occurring in a model of nonpharmacologically induced acute hypertension in which blood pressure was elevated by placing a clip on the abdominal aorta. The mechanism of increased cerebrovascular permeability was studied using HRP as a tracer and a quantitative estimate of pinocytosis was obtained to compare the results of this study with those previously observed in angiotensin-induced acute hypertension. 


\section{METHOD}

Female rats of the Wistar-Furth strain (Microbiological Associates Incs., Walkersville, Maryland) weighing 180-200 gms were anesthetized by the open drip method using methoxyflurane. The subclavian artery and femoral vein were cannulated using polyethylene catheters. The subclavian cannula was connected to a pressure transducer attached to a Grass polygraph for blood pressure measurements.

The experimental group of 10 animals received HRP Type II (Sigma Chemical Co., St. Louis, Mo.) in a dose of $50 \mathrm{mg}$ per $100 \mathrm{~g}$ body weight via the femoral vein cannula. Three minutes later a Heifetz clip was placed on the abdominal aorta for $2 \frac{1}{2}$ minutes. Blood was removed from the subclavian cannula for blood gas and $\mathrm{pH}$ estimations. The experiment was terminated by perfusion of fixative solution (Karnovsky, 1967) for 8 minutes.

Two groups of normotensive controls were subjected to the same procedures. as the test animals except that their aortas were not clipped. One group received HRP at the onset and the other group received saline instead of HRP. This was done to determine the effect of HRP itself on cerebrovascular permeability and pinocytosis in this model and to substantiate the results of our previous study (Nag et al, 1979) that HRP itself did not have any effect on this strain of rat.

Blocks of temporal, parietal, occipital and cingulate cortex were sectioned, using a tissue chopper, and placed in incubation medium (Hanker et al, 1977) for 12 minutes. Appropriate controls in which the substrate or hydrogen peroxide were omitted were also run. Sections from both cerebral hemispheres totalling approximately 60-80 per animal were examined by light microscopy and appropriate areas were post fixed in $1 \%$ osmium tetroxide, dehydrated through graded alcohols impregnated with propylene oxide and epon mixtures and embedded in Epon 812 for electron microscopy. Approximately 5 vessels per animal were sectioned for electron microscopy. Ultrathin sections were stained with aqueous uranyl acetate and lead citrate and examined in a Hitachi $\mathrm{H} 500$ electron microscope.

A quantitative estimate of pinocytosis in penetrating cortical arterioles was obtained by the same methods as described previously (Nag et al, 1979). Two arterioles from 3 hypertensive animals and 3 HRP controls and 1-2 nonpermeable vessels from the same hypertensive animals and saline controls were utilised for the morphometric studies as shown in Table 2. An overlapping series of electron micrographs were taken along the entire circumference of the vessel wall at a constant magnification and the endothelial cytoplasmic area excluding the area occupied by nuclei was determined using the Zeiss MOP-3 digital image analyser. The total number of pinocytotic vesicles and the mean vesicles $/ u^{2}$ of endothelial cytoplasm of the different groups was obtained and compared using the modified t-test and the one way analysis of variance with linear contrasts.

\section{RESULTS}

The $\mathrm{pH}$ and blood gases of normotensive and hypertensive animals (Table 1) was in the normal range.

\section{Blood Pressure:}

The mean maximum systolic blood pressure of both groups of controls was $130( \pm 15) \mathrm{mm} \mathrm{Hg}$. Test animals had a mean resting blood pressure of $125( \pm 12) \mathrm{mm} \mathrm{Hg}$. Clipping the abdominal aorta resulted in an immediate rise in blood pressure which measured $186( \pm 15) \mathrm{mm} \mathrm{Hg}$ (mean) at 30 seconds and remained around 180 $\mathrm{mm} \mathrm{Hg}$ during the period of experimentation (Fig. 1).
Control Rats:

Normotensive animals receiving HRP showed tracer in focal segments of occasional penetrating vessels in the 60 sections examined by light microscopy. This is consistent with our previous observations in this strain of rat.

The electron microscopic appearance of vessels of control animals was essentially the same as described by us previously and the descriptions in the literature.

\section{Hypertensive Rats:}

Five of the 10 hypertensive animals showed increased permeability to HRP in focal segments of 3-5 intracerebral cortical arterioles in the majority of the 60-80 sections from both cerebral hemispheres examined by light microscopy. Two additional animals showed increased vascular permeability in about 20 of the 60 sections examined. This degree of permeability alteration is greater than observed in controls. Permeable arteriolar segments were consistently located in the second and third cortical layers. In these permeable segments transverse lines representing tracer in the smooth muscle layer was identified (Fig. 2). The remaining 3 hypertensive animals resembled the controls.

Electron microscopic examination of numerous permeable arterioles of hypertensive animals demonstrated HRP confined to arteriolar walls with minimal extravasation into the surrounding neuropil. Tracer was present in endothelial and smooth muscle basement membranes, and in the adventitia (Fig. 3). Serial sectioning of permeable arterioles demonstrated

TABLE 1

Arterial Blood Gases: Mean and Standard Deviation

pH Pa02 PaC02

\section{NORMOTENSIVE}

$\begin{array}{lrrr}\text { Saline Controls }(5) & 7.32( \pm 0.05) & 104( \pm 12.2) & 46( \pm 4.5) \\ \text { HRP Controls }(5) & 7.34( \pm 0.02) & 102( \pm 7.8) & 45( \pm 2.51) \\ \text { HYPERTENSIVE }(10) & 7.31( \pm 0.03) & 94( \pm 11.0) & 47( \pm 3.20)\end{array}$




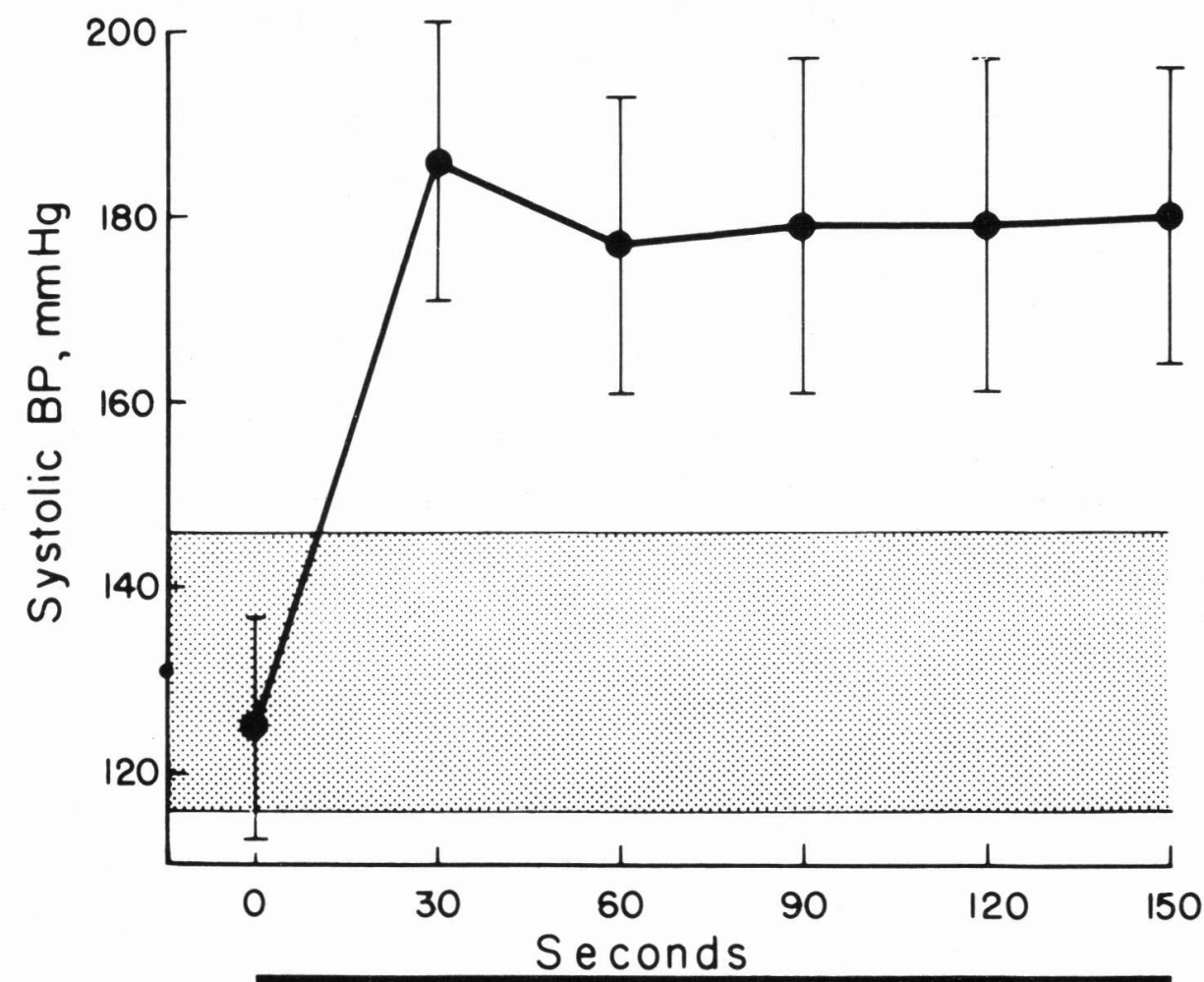

Aorta Clipped

Figure 1-Summary of blood pressure rise following application of clip to abdominal aorta. Mean maximum systolic blood pressure values and standard deviation are shown. The shaded area represents the mean maximum systolic blood pressure and standard deviation of the two groups of normotensive controls.

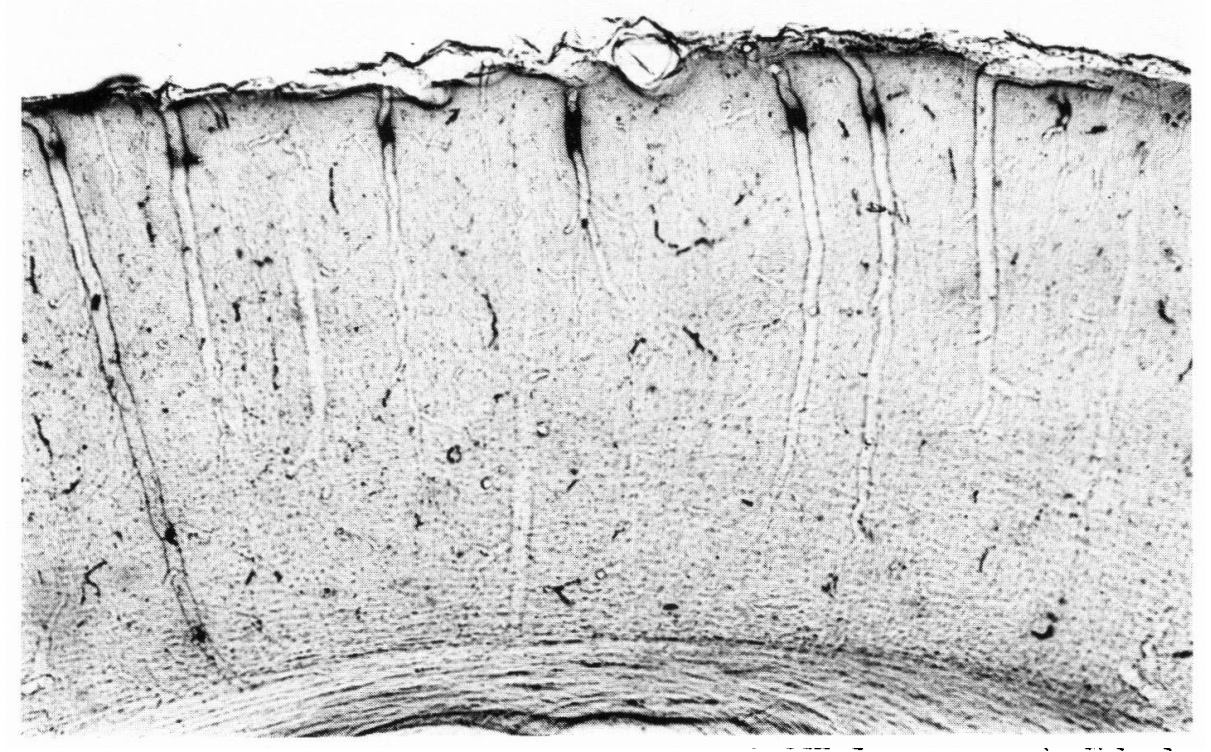

Figure 2- Parietal cortex of a hypertensive animal demonstrating increased permeability to HRP in focal segments of several penetrating arterioles. $X 40$.

numerous pinocytotic vesicles along most of the circumference of the vessel wall (Fig. 4) at levels where permeability was maximum. In this segment rows of vesicles containing tracer were occasionally present extending across the width of the endothelium. Above and below this level although tracer was demonstrable in vessel walls fewer pinocytotic vesicles were observed. Few capillaries and venules showed tracer in their walls. The interendothelial junctions of all three types of vessels were intact with no evidence of widening or disruption of junctions (Fig. 5) nor was tracer observed along the entire length of the interendothelial space. Occasional vessels revealed the presence of tracer diffusely in endothelial cytoplasm.

The nonpermeable arterioles of hypertensive animals were similar to the vessels of controls receiving HRP. Occasional vesicles containing HRP were observed in the endothelium.

\section{QUANTITATIVE MORPHOMETRY}

Normotensive Rats: Animals receiving only saline had a mean of 5 vesicles per $\mu \mathrm{m}^{2}$ of arteriolar endothelial cytoplasm (Table 2). Animals which received HRP had the same number of vesicles per $\mu \mathrm{m}^{2}$ of endothelial cytoplasm demonstrating that HRP itself did not alter pinocytosis in these rats. In these animals eight percent of vesicles contained tracer.

Hypertensive Rats: Permeable vessels of these animals had a mean of 11 vesicles per $\mu \mathrm{m}^{2}$ of arteriolar endothelial cytoplasm, a value which is significantly higher $(p>0.001)$ than observed in vessels in control animals. The nonpermeable vessels of these animals had 5 vesicles per $\mu \mathrm{m}^{2}$ of endothelial cytoplasm, a value similar to that observed in control animals. The percentage of vesicles transporting tracer was also significantly higher in the permeable segments being $66 \%$ as compared with $10 \%$ in the nonpermeable segments.

\section{DISCUSSION}

This study has demonstrated that increased permeability of intracerebral cortical vessels occurs in a model of acute hypertension in which blood pressure elevation is produced by nonpharmacological means. Further more, the principal mechanism of increased permeability is enhanced pinocytosis. 


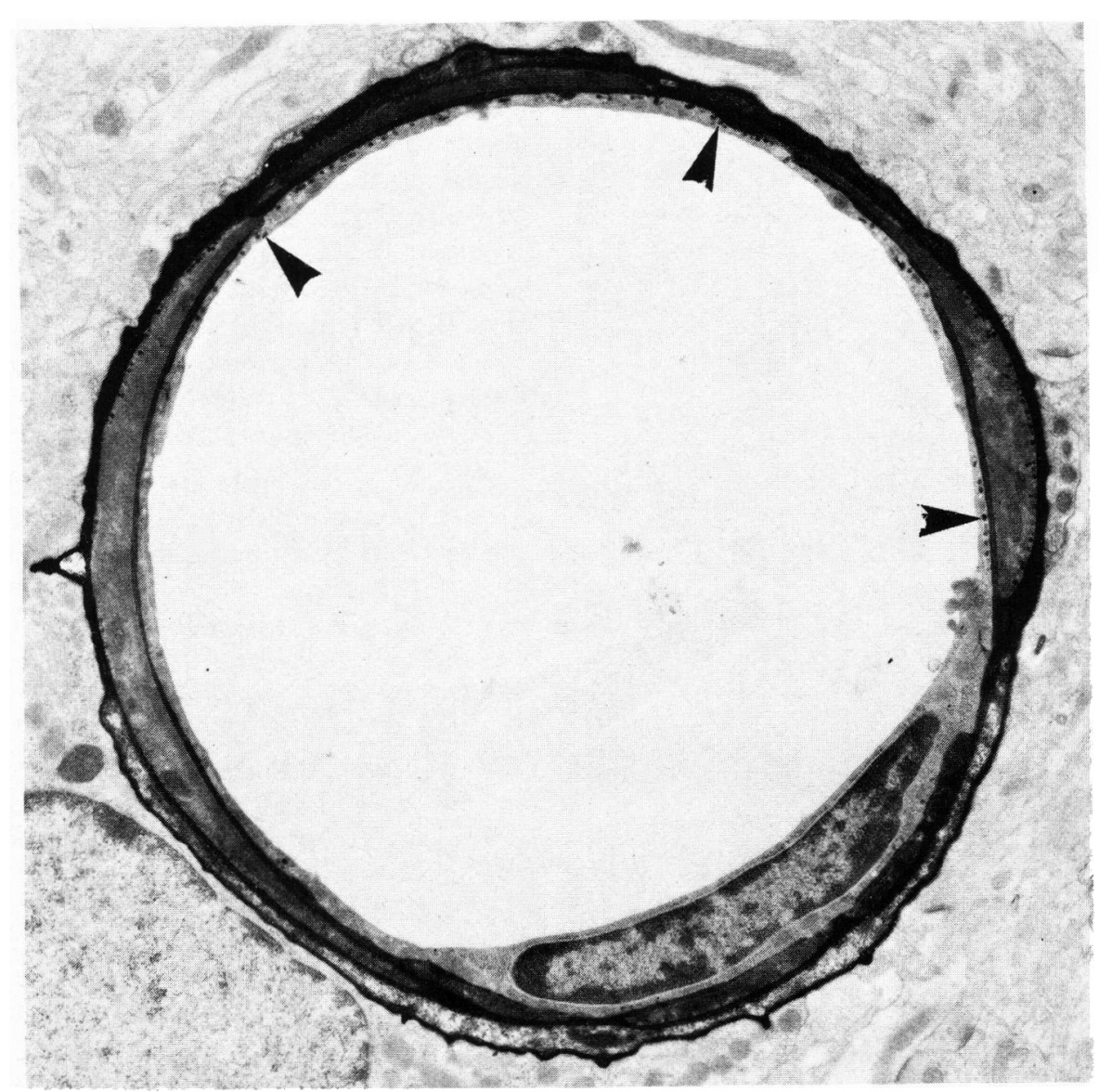

Figure 3-Tracer is present in all layers of the wall of a penetrating cortical arteriole of a hypertensive rat. Note the numerous pinocytotic vesicles along the circumference of the vessel wall (arrowheads) x 6,900. study has many similarities to our previous observations in angiotensininduced acute hypertension. In both models arterioles situated in the temporal, parietal and occipital areas demonstrate increased permeability in focal segments present in the second and third cortical layers. In order to determine the mechanism of the permeability change in the present model permeability studies were done $2 \frac{1}{2}$ minutes after onset of acute hypertension when tracer was still confined to vessel walls. Our previous study (Nag et al, 1977) has demonstrated that at later time intervals tracer extravasates from the vessel wall into the extracellular spaces of the surrounding neuropil and the mechanism of the permeability change becomes unclear. In the present study only $70 \%$ of hypertensive animals demonstrated increased cerebrovascular permeability. This is in agreement with our previous findings (Nag et al, 1977) and those of other authors (Johansson and Linder, 1974) that only about $70 \%$ of animals with acute hypertension demonstrate increased cerebrovascular permeability. This may be related to the rapidity of the blood pressure rise and the maximum level attained, although
Similar models of nonpharmacologically induced acute hypertension have been studied in the past. Meyer et al, 1960, produced a sudden rise in blood pressure and a proportional rise in the intracranial pressure of monkeys and cats by aortic clamping. Prolonged hypertension produced by this method resulted in cerebral edema which led to tentorial herniation and death in 8-32 hours. Although these authors found no change in BBB permeability to trypan blue, Johansson and Linder, 1974, demonstrated increased BBB permeability in dogs with acute hypertension produced by aortic compression. In the latter study Evans blue was used as a marker of BBB permeability alterations; the types of vessels showing increased permeability and the mechanism by which increased permeability occurred were not studied.

The permeability alterations in intracerebral vessels observed in this

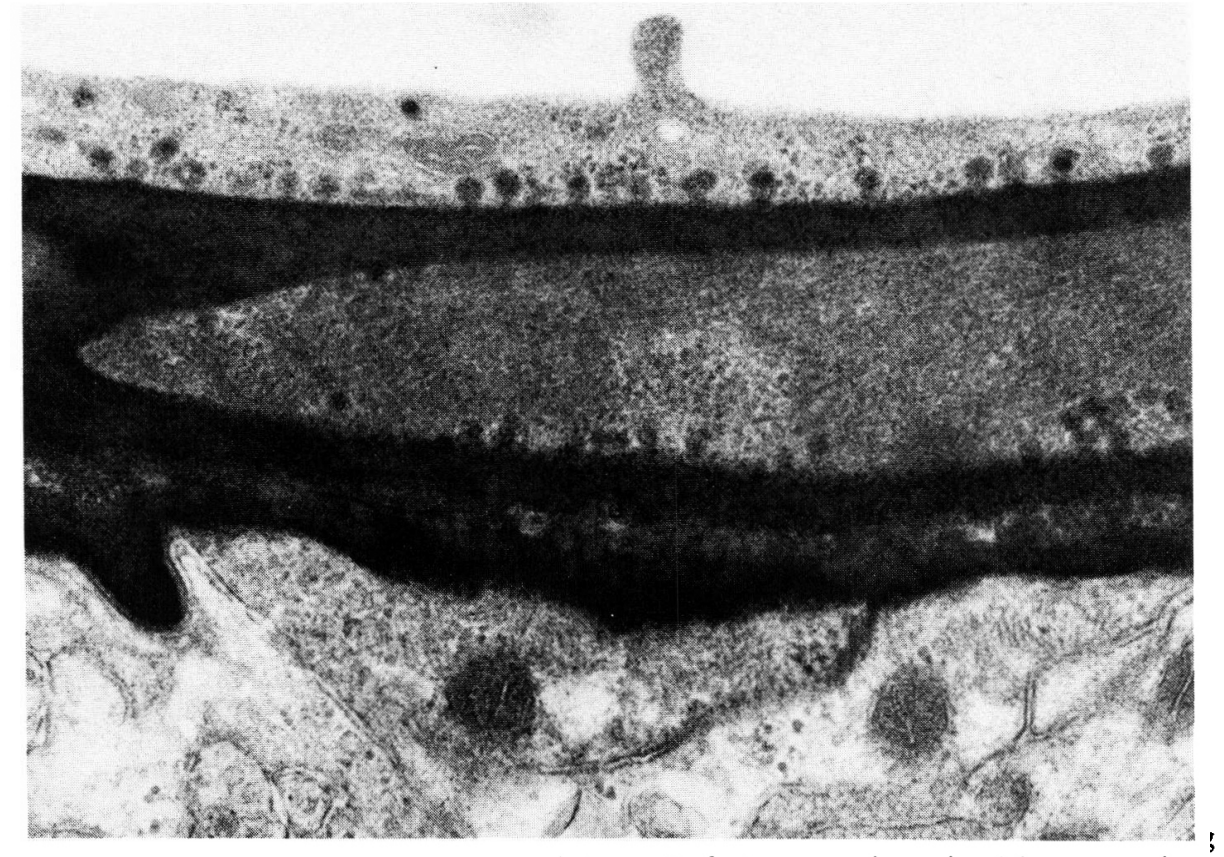

numerous pinocytotic vesicles in both the luminal and abluminal portion of the endothelium. Tracer is also present in the basement membranes and pinocytotic vesicles of the smooth muscle cells and in the adventitia. $X 40,600$. 


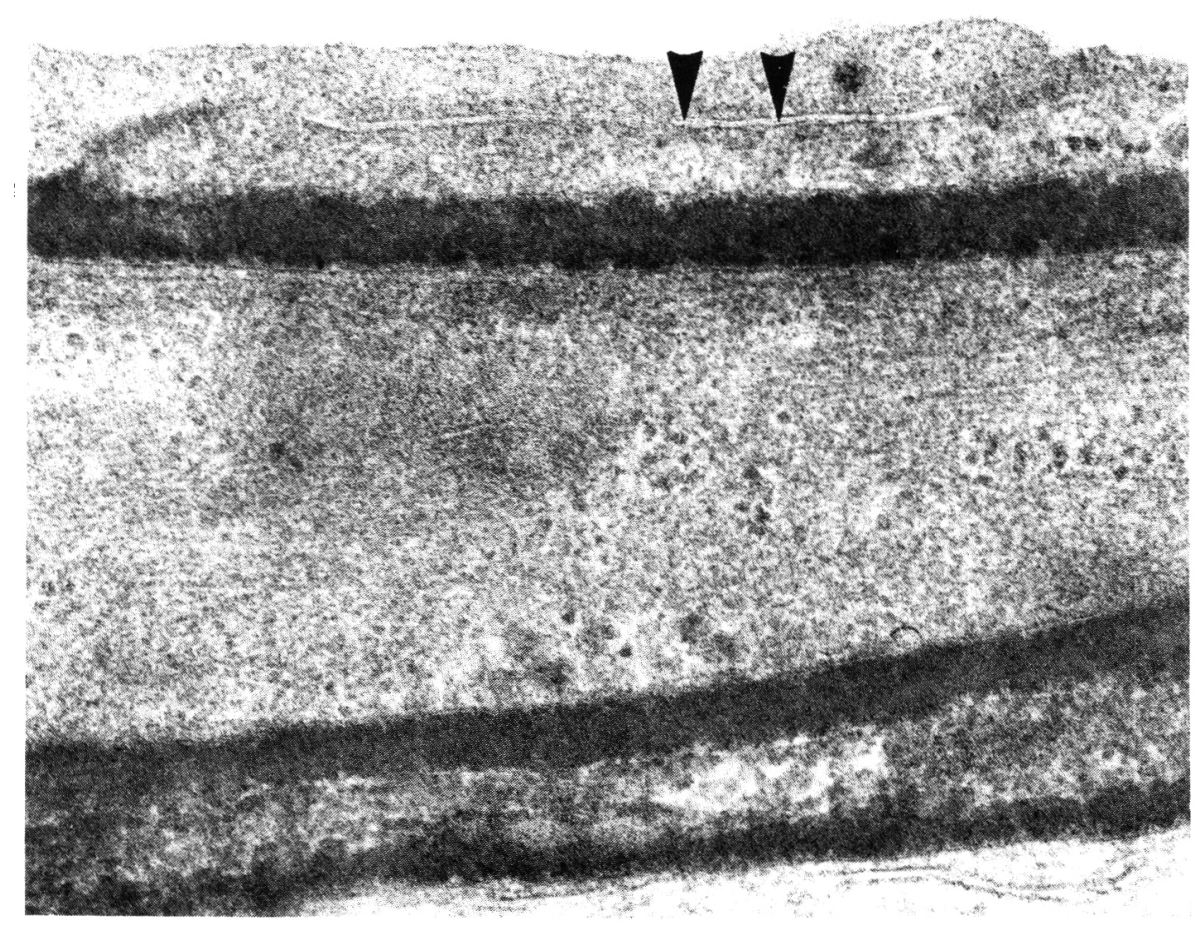

Figure 5 - A segment of permeable arteriolar wall of a hypertensive animal showing tracer in all layers of the wall, and at the abluminal end of an interendothelial space which shows intact tight junctions (arrowheads) X 51,500 .

TABLE 2

Mean Vesicles per $\mu m^{2}$ of Arteriolar Endothelial Cytoplasm of Normotensive and Hypertensive Animals

\section{ARTERIOLAR
SEGMENTS}

\section{NORMOTENSIVE}

HRP Controls (6)

HYPERTENSIVE

Permeable (6)
Saline Controls (5)

Nonpermeable (5)

\section{MEAN VESICLES/ $\mu \mathrm{m}^{2}$ ENDOTHELIUM}

\% VESICLES WITH HRP

$$
\begin{aligned}
& 5.49 \pm 1.06 \\
& 5.54 \pm 0.78
\end{aligned}
$$

$11.30 \pm 1.21$

$4.76 \pm 0.55$ tension. These pinocytotic vesicles undoubtedly represent parts of transendothelial channels that have been demonstrated in cerebral endothelium in other models (Beggs and Waggener, 1979; Lossinsky et al, 1979).

In a previous study (Nagy et al, 1979) disruption of endothelial junctions was considered to produce cerebrovascular permeability alterations in acute hypertension induced by aramine and by infusion of saline as a bolus of $0.63 \mathrm{ml}$ per second for 8 seconds. However, the illustrations provided do not demonstrate HRP along the entire length of the interendothelial space and tracer present at the abluminal end of the interendothelial space can be interpreted as back diffusion from adjacent endothelial basement membranes containing tracer. These studies were done 10 minutes after the onset of acute hypertension. Our present study done $21 / 2$ minutes after the onset of acute hypertension failed to demonstrate disruption of tight junctions or the presence of HRP along the entire length of the interendothelial space. It can be concluded that in the early period following acute hypertension massive disruption of junctions does not occur. However it might be argued that HRP is not a suitable marker for minor degrees of alterations in junctions.

Diffuse uptake of tracer in the cytoplasm of isolated endothelial cells was occasionally observed in this study. These diffusely labelled cells were not associated with presence of tracer in endothelial basement membranes or in the adjacent vascular lumen. Diffuse endothelial cytoplasmic uptake of HRP has been considered as being artefactual, possibly related to cell membrane damage during fixation (Karnovsky, 1967; Brightman et al, 1970). In our experience, and that of others, it is seldom associated with the presence of HRP beyond the end othelium. However, critical proof of its artefactual nature is not yet a vailable. If diffuse cytoplasmic uptake of HRP is a mechanism of permeability change in acute hypertension, it is quantitatively of little importance. 
The similarity between the observations of the present study and those made previously in angiotensininduced hypertension suggest that the alterations in cerebrovascular permeability observed previously are not a direct effect of exogenous angiotensin and occur in acute hypertension irrespective of the method used to elevate the blood pressure. This is further supported by our recent observations (Nag et al, 1980) in rats which develop hypertension spontaneously on a genetic basis and have normal blood levels of angiotensin and normal values of renin (Sen et al, 1972; Sokabe, 1965). The mechanism of early cerebrovascular permeability alterations in these animals is enhanced pinocytosis.

Our studies suggest that during the early phase of acute severe hypertension, pinocytosis is the principal mechanism by which plasma proteins are transported across the BBB. This raises the osmotic pressure of tissues and leads to passage of water and production of cerebral edema.

\section{ACKNOWLEDGEMENTS}

The authors wish to thank Mrs. Marian Arnold, Mr. Norman Meyers and Mrs. Patricia Scilley for their technical assistance.

\section{REFERENCES}

BEGGS, J.L., WAGGENER, J.D. (1979). The acute microvascular responses to spinal cord injury. Adv. Neurol. 22 eds, Thompson, R.A. and Green, J.R., Raven Press, New York, 179-189.

BRIGHTMAN, M.W., KLATZO, I., OLSSON, Y., REESE, T.S. (1970). The blood-brain barrier to proteins under normal and pathological conditions. J. Neurol. Sci. 10: 215-239.

HANKER, J.S., YATES, P.E., METZ, C.B., RUSTIONI, A. (1977). A new specific, sensitive and non-carcinogenic reagent for the demonstration of horseradish peroxidase. Histochem. J. 9: 789-792.

HANSSON, H-A, JOHANSSON, B., BLOMSTRAND, C. (1975). Ultrastructural studies on cerebrovascular permeability in acute hypertension. Acta Neuropathol. (Berl.) 32: 187-198.

JOHANSSON, B., LINDER, L-E. (1974). Blood-brain barrier dysfunction in acute arterial hypertension induced by clamping of the thoracic aorta. Acta Neurol. Scand. 50: 360-365.

KARNOVSKY, M.J. (1967). The ultrastructural basis of capillary permeability studied with peroxidase as a tracer. J. Cell. Biol. 35: 213236.

LOSSINSKY, A.S., GARCIA, J.H., IWANOWSKI, L., LIGHTFOOTE, W.E. Jr. (1979). New ultrastructural evidence for a protein transport system in endothelial cells of gerbil brains. Acta Neuropathol. (Berl.) 47: $105-110$.
MEYER, J.S., WALTZ, A.G., GOTOH, F. (1960). Pathogenesis of cerebral vasospasm in hypertensive encephalopathy. Neurology 10: $735-744$.

NAG, S., ROBERTSON, D.M., DINSDALE, H.B. (1977). Cerebral cortical changes in acute experimental hypertension. An ultrastructural study. Lab. Invest. 36: 150161.

NAG, S., ROBERTSON, D.M., DINSDALE, H.B. (1979). Quantitative estimate of pinocytosis in experimental acute hypertension. Acta Neuropathol. (Berl.) 46: 107116.

NAG, S., ROBERTSON, D.M., DINSDALE, H.B. (1980). Morphological changes in spontaneously hypertensive rats. Acta Neuropathol. (Berl.) 52: 27-34.

NAGY, Z, MATHIESON, G., HUTTNER, I. (1979). Blood-brain barrier opening to horseradish peroxidase in acute arterial hypertension. Acta Neuropathol. (Berl.) 48: 45-53.

PETITO, C.K., LEVY, D.E. (1980). The importance of cerebral arterioles in alterations of the blood-brain barrier. Lab Invest. 43: 262-268.

SEN, S., SMEBY, R.R., BUMPUS, F.M. (1972). Renin in rats with spontaneous hypertension. Circ. Res. 31: 876-880.

SOK ABE, H. (1965). Renin-angiotensin system in the spontaneously hypertensive rat. Nature 205: 90.

WESTERGAARD, E., VAN DEURS, B., BR $\phi N D S T E D$, H.E. (1977). Increased vesicular transfer of horseradish peroxidase across cerebral endothelium, evoked by acute hypertension. Acta Neuropathol. (Berl.) 37: 141-152. 